\title{
In vivo Assessment of APPJ Discharge on the Earthworm: Coelomic TAC and MDA Levels, Cell Death and Tissue Regeneration
}

\section{Neda Gholami}

University of Mazandaran

Abasalt Hosseinzadeh Colagar ( $\nabla$ ahcolagar@umz.ac.ir)

University of Mazandaran https://orcid.org/0000-0001-6536-8250

Mohammad Hossein Sinkakarimi

University of Mazandaran

Farshad Sohbatzadeh

University of Mazandaran

\section{Research Article}

Keywords: Cold atmospheric plasmas, Total antioxidant capacity, Malondialdehyde, Earthworms, Catalase

Posted Date: July 26th, 2021

DOl: https://doi.org/10.21203/rs.3.rs-663391/v1

License: (9) This work is licensed under a Creative Commons Attribution 4.0 International License. Read Full License

Version of Record: A version of this preprint was published at Environmental Science and Pollution Research on October 12th, 2021. See the published version at https://doi.org/10.1007/s11356-02116838-3. 


\section{Abstract}

The cold atmospheric pressure plasma jet (APPJ) is one of the effective tools with medical applications that its positive effects have been reported by various researchers, including sterilization of liquid and solid surfaces, treatment of chronic wounds, treatment of cancer tumors, and blood clots. This study investigated the effects of APPJ discharge on the two species of Earthworms (Aporrectodea trapezoides and Eisenia fetida). The APPJ discharge for different time durations, zero as a blank, 5, 10, 20, and 30 seconds, on these two species. Then some of these effects on the worms, including regeneration ability to miss segments, Malondialdehyde (MDA), catalase activity (CAT), total antioxidant capacity (TAC), cell death, total proteins, and protein profile in the coelomic fluid were investigated. Results showed levels of TAC and CAT increased after plasma treatment. In addition, a significant change was not observed in MDA levels and cell death. In summary, it can be concluded that APPJ exposure up to 40 seconds didn't inhibit effects on the TAC levels of the earthworms and the defense system was able to fight oxidative stress and by increasing the expression of some proteins APPJ lead to better regeneration.

\section{Introduction}

Plasma, as the fourth state of matter, is an ionized gas capable of producing reactive species of oxygen, nitrogen, free radicals, electrons, ions, and neutral particles (Lee et al. 2009; Lu et al. 2016). The use of low-temperature plasma by applying two dielectric barrier discharge (DBD) and plasma jet devices has been expanded in cells and tissues as well as in biology (Graves et al. 2014; Xu et al. 2015). Such applications may include cancer treatment, surface sterilization due to its ability to eliminate bacteria, blood coagulation, dentistry, and wound healing and regeneration (Hung et al. 2016). The process of plasma formation is accompanied by many chemical reactions. These reactions create particles that can react with different materials, including the bio-macromolecules. According to the studies, the major effect of this new technology is due to the presence of reactive oxygen species/ROSs and nitrogen species/RON (Keidar et al. 2011). RNS are produced in animals starting with the reaction of nitric oxide $(\cdot \mathrm{NO})$ with superoxide $\left(\mathrm{O}_{2}{ }^{--}\right)$to form peroxynitrite $\left(\mathrm{ONOO}^{-}\right)$, via the enzymatic activity of inducible nitric oxide synthase $2\left(\mathrm{NOS}_{2}\right)$ and NADPH oxidase, respectively (Dröge 2002). ROS include superoxide anion $\left(\mathrm{O}^{-}\right)$, hydroxyl radical $(\mathrm{OH} \cdot)$, hydrogen peroxide $\left(\mathrm{H}_{2} \mathrm{O}_{2}\right)$, nitric oxide $(\mathrm{NO})$, peroxynitrite $\left(\mathrm{ONOO}^{-}\right)$, and so on (Kalghatgi et al. 2011).

ROSs are involved in the process of wound healing, which requires the presence of various cell types such as immune cells, endothelial cells, fibroblasts, and keratinocytes. The ability of the plasma to accelerate the proliferation of fibroblasts and keratinocytes and the production of growth factors makes it possible to use it to heal wounds (Wilgus 2008). Recently several studies demonstrated the effects of different plasma treatment times on wound healing skin in mice. Xu et al. (2015) demonstrated appropriate doses of radicals can stimulate the proliferation of endothelial cells and fibroblasts, whereas excessive radical doses can cause cell death (Xu et al. 2015). Nastuta et al. (2011) used Helium jet plasma to examine the effect of the wound and biochemical parameters on Wistar rats' skin. They concluded direct plasma 
treatment of wounds modifies the dynamics of the skin regeneration process (Nastuta et al. 2011). In this paper, we examined the effect of an argon plasma jet on the process of regeneration in earthworms with an emphasis on oxidative effects. Among the eukaryotic species, earthworms have a high potential for the regeneration of the lost body segments. However, the location of the segment cut determines the success of the regeneration (Brockes et al. 2001). Since the excessive production of free radicals in tissues and high levels of ROS may lead to oxidative stress, lipid peroxidation, and cell death (Liu et al. 2009), many antioxidant enzymes such as catalase involved in the antioxidant defense are tasked to eliminate the harmful effects of ROS aimed at combating the oxidative stress (Porter 1984). Literature review showed, no investigation studied the effects of APPJ on the regeneration ability of earthworms and associated molecular and biochemical responses Just one case; Laroussi used a flatworm model (Planaria). it was concluded that exposure to nonthermal plasma does not cytotoxic effects on the growth of cell regeneration in planaria (Laroussi 2015). It seems this item was provided in this study for the first time. Therefore, this study aims to evaluate the ability to regeneration and changes in oxidative stress biomarkers, including malondialdehyde (MDA), total antioxidant capacity (TAC), Catalase activity, DNA damage (using TUNEL assay), and protein profile exchange by SDS-PAGE in two species of earthworms called Eisenia Fetida and Aprocteda trapezoides in response to APPJ.

\section{Materials And Methods}

\section{Earthworms and substrate}

Two earthworm species including $A$. trapezoides (Weight: $930 \pm 117 \mathrm{mg}$; length: $11 \pm 1 \mathrm{~cm}$ : segments: $139 \pm 9$ ) and E. fetida (Weight: $585 \pm 70 \mathrm{mg}$; length: $9 \pm 1 \mathrm{~cm}$ : segments: 104 \pm 12 ) were collected by hand sorting from a rural area (Kaleno; N $36^{\bullet} 30^{\prime}$; E 51 ${ }^{\bullet} 14^{\prime}$ ) in the north of Iran and identified according to common keys, which reported by Sinkakarimi et al. (2020). These species were cultured in the laboratory by growing in sterilized host soil and cattle manure, respectively (Lowe and Butt 2007).

\section{APPJ device}

The jet plasma is produced by an APPJ device, the detailed information of this system has been described in the previous study (Hosseinzadeh Colagar et al. 2020). The specifications of this device can be summarized as follows: $99 \%$ argon and $1 \%$ air; gas flow, $1 \mathrm{l} / \mathrm{min}$; a sinusoidal alternating voltage with a peak voltage of $8 \mathrm{kV}$ and a frequency of $18.56 \mathrm{kHz}$; and Temperature and humidity of the room were $25^{\circ} \mathrm{C}$ and $70 \%$, respectively. The APPJ emission spectra in the wavelength range of $300-900 \mathrm{~nm}$ were captured and some highlighted spectral lines were shown in figure 1.

\section{Regeneration test}

Gut cleaned earthworms were rinsed with deionized water, cooled down with a wet block of ice, and amputated quickly with a sharp scalpel from 24 segments after clitellum under a dissecting microscope. 
Posterior segments were removed and anterior segments saved. After amputation, earthworms were transferred to sterilized media for one day to heal the wounds. Then, earthworms were anesthetized using $10 \%$ ethanol and exposed to APPJ for 0 (as control), 5, 10, 20, and 30 seconds. Host soil and cow dung respectively used for $A$. trapezoides and $E$. fetida as the substrate for culturing in polyethylene containers (2 litter). Cow dung was used as food during the test for $A$. trapezoides. After three months, each earthworm was placed on a block of wet ice, and the length of regenerating segments measured ( $\mathrm{mm} /$ individual), under a dissecting microscope. These manipulations were designed to observe the effects of different treatments of APPJ on lengths of regeneration.

\section{Molecular and biochemical response}

Three gut-cleaned earthworms per treatment were homogenized together in an extraction buffer (50 mM Tris-HCl, pH 7.5; $0.25 \mathrm{M}$, Sucrose; $1 \mathrm{mM}^{\mathrm{EDTA}} \mathrm{Na}_{2}, \mathrm{pH} 7.5$ ) in a $1 / 4 \mathrm{w} / \mathrm{v}$ ratio using a homogenizer (IKA T18 Ultra-Turrax, USA) for $30 \mathrm{~s}$ at $10000 \mathrm{rev} / \mathrm{min}$. Homogenates were centrifuged at 10,000 rpm for $15 \mathrm{~min}$ in $4{ }^{\circ} \mathrm{C}$. After centrifugation, the supernatants were collected and stored at $-80^{\circ} \mathrm{C}$ until required for Molecular and biochemical analysis (Chen et al. 2011; Liu et al. 2015). Malondialdehyde content was used as a biomarker of lipid peroxidation based on the thiobarbituric acid assay according to the methods described by Ohkawa et al. (1979) with some modification. TAC was evaluated using the ferric reducing ability of plasma (FRAP) according to the method described by Benzie and Strain (1996). The content of MDA and TAC was calculated using a molar extinction coefficient of $1.56 \times 105 \mathrm{M}^{-1} \mathrm{~cm}^{-1}$ by measuring the absorption at 532 and $593 \mathrm{~nm}$, respectively, using a spectrophotometer. Catalase activity was evaluated using $\mathrm{H}_{2} \mathrm{O}_{2}$ as substrate according to the Aebi method (Aebi 1984). The content of catalase was calculated using the molar extinction coefficient of $0.0394 \mathrm{mM}^{-1} \mathrm{~cm}^{-1}$. Changes in absorbance were measured at $240 \mathrm{~nm}$ and the linear decrease in absorbance was recorded over 3 min by a spectrophotometer.

\section{SDS-PAGE of total protein}

Discontinuous sodium dodecyl-sulfate polyacrylamide gel electrophoresis (SDS-PAGE) was performed according to Laemmli (1979) with $15 \%$ acrylamide gels and $50 \mu \mathrm{g}$ of the coelomic fluid proteins per lane was loaded. Staining with Coomassie Brilliant Blue R250 was used to localize the protein bands. Molecular weights were calculated according to prestained molecular weight standards. The electrophoresis run was carried out with $70 \mathrm{~V}$ for $3.5 \mathrm{~h}$ per plate towards the cathode. Bradford (1976) method was used for the determination of total protein, using by measuring absorbance at 593 $\mathrm{nm}$ and bovine serum albumin/BSA as a standard.

\section{TUNEL assay}


Five primary segments were separated from the irradiated plasma area and homogenated. TUNEL (terminal dUTP nick-end labelling) assay was used for the evaluation of DNA fragmentation. This test was performed by an in situ cell death detection kit (Avicenna Research Institute, Iran) according to the manufacturer's standard protocol with 200 cells for each sample.

\section{Statistical analysis}

Statistical analyses carried out using SPSS ver. 19.0 software. The normality of data was tested using the Shaprio-Wilk test. Datasets were analyzed using a general linear model (GLM) with Turkey's pairwise comparison to assess the significant difference between groups. The statistical significance levels were set at $p<0.05$.

\section{Results}

\section{APPJ effects on regeneration lengths and coelomic fluid proteins}

Atmospheric plasma jet exposure induced significant effects on regeneration ability in earthworms (Fig $2 A)$. The A. trapezoides and $E$. fetida had greater lengths of regeneration after 20 and $30 \mathrm{~s}$ of exposure to APPJ $(p<0.05)$.

Analysis of SDS-PAGE from coelomic fluid proteins of E. fetida and A. trapezoides species showed that protein patterns of bands in the two species were similar (Fig 2C). The strongest protein band with the molecular mass between 14-20 kDa was observed in both treatments and In general, no significant difference was observed in the expression of proteins.

\section{Effects of APPJ on cell death, TAC, CAT, and MDA}

The effects of the APPJ discharge on the chromosomal degradation of coelomic cells were assayed by TUNEL test. This method is based on template-independent addition of labeled nucleotides to the free 3'$\mathrm{OH}$ ends of fragmented DNA by the enzyme terminal deoxynucleotidyl transferase and has been widely used as a specific marker for apoptosis. Recent evidence, however, has questioned its specificity as an unequivocal indicator of apoptosis (MacManus et al. 1994; Kraupp et al. 1995; Yasuda et al. 1995). Results showed that Atmospheric pressure plasma jet did not have significant effects on amounts of TUNEL positive cells in both species ( $p>0.05$ ) (Fig 3). Although TUNEL positive cells increased with increasing time of exposure, this increase wasn't significant.

Atmospheric pressure plasma jet didn't have any significant effects on MDA content $(p>0.05)$, but this effect was significant for TAC and CAT in both species $(p<0.05)$. Total antioxidant capacity and CAT, had higher levels after 20 and $30 \mathrm{~s}$ of exposure to APPJ related to control $(p<0.05)$. 


\section{Discussion}

The APPJ consisted of many reactive species including excited argon atoms, $\mathrm{OH}$ radicals, nitrogen. As shown in Fig. 1, APPJ discharge was dominated by electron impact ionization. Peaks corresponding to $\mathrm{N}_{2}$ were measured between 310 and $440 \mathrm{~nm}$ and $\mathrm{OH}$ radical at $308 \mathrm{~nm}$ were detected. These free radicals and chemical species play an important role in the interaction between plasma and cells. In the present study, plasma irradiation showed a positive effect on the ability of regeneration in the studied species. Hypoxy induces angiogenesis during wound healing, and ROS incurs activation of Macrophages, Fibroblasts, endothelial cells, and keratinocytes and as a result, VEGF (vascular endothelial growth factor) production. It has been reported that exogenous ROS stimulate the induction of VEGF expression in various types of cells such as endothelial cells, smooth muscle cells, and macrophages. It's important to note that the appropriate doses of radicals can stimulate the proliferation of the cells which are effective in the process of tissue repair (such as endothelial cells and fibroblasts), while high doses of radicals can cause cell death through apoptosis or necrosis (Xu et al. 2015).

Some types of earthworms have great potentials for regenerating lost body segments, although, environmental conditions such as temperature and nutrition can affect regeneration (Herlant-Meewis 1964). During the wound healing process, increasing antioxidant levels will reduce ROS levels as well as oxidative stress resulting in wound healing (Kim and Byzova 2014).

The findings show that plasma-generated free radicals can trigger apoptosis by inflicting damage to the mitochondrial membrane. $\mathrm{H}_{2} \mathrm{O}_{2}$ and $\mathrm{NO}_{X}$ are the plasma-generated species that cause cell proliferation as well as cell death. $\mathrm{H}_{2} \mathrm{O}_{2}$ can induce apoptosis and necrosis while NOx can cause cell death through double-strand DNA breaks (Partecke et al. 2012; Schlegel et al. 2013). Catalase (CAT) is one of the antioxidant enzymes that can remove plasma-induced ROS which plays a key role in the removal of hydrogen peroxide. One of the antioxidant functions of catalase is lowering the risk of hydroxyl radical formation from $\mathrm{H}_{2} \mathrm{O}_{2}$ (Jones 2001). A significant increase in it indicates the defense function of this enzyme as one of the main components of the antioxidant defense system, as well as the severity of oxidative stress. When oxidative stress exceeds antioxidant defenses, the defense system will not generate more catalase. The degree of RS-induced contamination and the cell's ability to handle the stress can affect the extent of enzyme activation or inactivation (Misra et al. 2016). Due to the existence of a wide variety of antioxidant compounds in serum and tissues, it is difficult to measure them individually. Moreover, separate measurements of various antioxidants' activities can not indicate their full functions due to their overlapping activities. consumption or production and consumption, leading to oxidative stress (Pinzani et al. 1998). In this case, the increase in TAC besides no significant change in MDA probably proves that the defense system of the APPJ treated cells has not been compromised. ROSinduced toxicity is usually associated with increased levels of fatty peroxides and MDA. Malondialdehyde is the product of the decomposition of unsaturated fatty acid peroxides in the cellular membranes of organisms (Lin et al. 2010). Shalata and Tal (1998) proposed that one of the most damaging effects of ROS is lipid peroxidation, which can be indicated by MDA determination. Therefore, MDA is often used as an indicator of oxidative damage (Xue et al. 2009). The cytotoxic effect of plasma may overcome the 
antioxidant capacity in earthworms and reduce TAC due to exposure to high doses of plasma or longer exposure.

\section{Conclusion}

According to the present study, cold atmospheric plasma irradiation can have a positive effect on the ability to regenerate lost segments in earthworms. Since plasma irradiation is associated with the production of reactive oxygen species and nitrogen, organisms produce antioxidants as a practical way of coping with stress and preventing oxidant overcoming of these conditions. No significant change in MDA and cell death could be related to antioxidant efficacy.

\section{Declarations}

\section{Ethical Approval}

Informed consent was obtained from all subjects, and the study protocol was approved by the ethics committee of the University of Mazandaran and conducted in accordance with Iran National Committee for Ethics in Biomedical Researches.

\section{Consent to Participate}

As corresponding author, I confirm that the manuscript has been read and approved for submission by all the named authors.

\section{Consent to Publish}

All authors would like to submit this manuscript, to be considered for publication as a Research Article, in the ESPR Journal. And declare that it is original, has not been published before and is not currently being considered for publication elsewhere.

\section{Authorship Contribution Statement}

We confirmed that, all authors were involved in writing this article. A. Hosseinzadeh Colagar, as a supervisor of MSc student, in the Conceptualization, Methodology, Software; N. Gholami, as a MSc student, in the Data curation, Writing- Original draft preparation; M.H. Sinkakarimi and F. Sohbatzadeh, as Co-advisors of MSc student, in the Material preparing, Data analysis, Reviewing and Editing.

\section{Funding}


This study was supported by a grant from the University of Mazandaran, dedicated to the MSc thesis of Neda Gholami (Registered No: 1396342).

\section{Availability of Data and Materials}

The datasets generated and analyzed during the current study are available from the corresponding author on reasonable request.

\section{Conflict of Interest}

There is no conflict of interest to declare.

\section{Acknowledgments}

We appreciate all the colleagues who collaborated with us in this study.

\section{References}

1. Aebi H (1984) Catalase in vitro. In methods in enzymology (Vol. 105, pp. 121-126). Academic Press.

2. Benzie IFF, Strain JJ (1996) The ferric reducing ability of plasma (FRAP) as a measure of antioxidant power: The FRAP Assay, Analytical Biochemistry 76: 70-76.

3. Bradford M (1976) A rapid and sensitive method for the quantitation of microgram quantities of protein utilizing the principle of protein-dye binding. Analytical Biochemistry 254: 248-254.

4. Brockes JP, Kumar A, Velloso CP (2001) Regeneration as an evolutionary variable. The Journal of Anatomy 199(1-2): 3-11.

5. Chen C, Zhou Q, Liu S, Xiu Z (2011) Acute toxicity, biochemical and gene expression responses of the earthworm Eisenia fetida exposed to polycyclic musks. Chemosphere 83: 1147-1154.

6. Dröge W (2002). Free radicals in the physiological control of cell function. Physiological Reviews 82(1): 47-95.

7. Graves DB (2014) Reactive species from cold atmospheric plasma: implications for cancer therapy, Plasma Process and Polymers 11(12):1120-1127.

8. Herlant-Meewis H (1964) Regeneration in annelids. Advances in Morphogenesis 4: 155-215.

9. Hosseinzadeh Colagar A, Hasheminasabgorji E, Mohadjerani M, Sohbatzadeh F, Karami H (2020) APPJ discharge effects on human factor VIII: Ag level in healthy and hemophilia A patient. Iranian Journal of Science and Technology (Sciences) 44: 13-19.

10. Hung YW, Lee LT, Peng YC, Chang CT, Wong YK, Tung KC (2016). Effect of a nonthermal-atmospheric pressure plasma jet on wound healing: An animal study. Journal of the Chinese Medical Association 79(6):320-328. 
11. Jones $P$ (2001) Roles of water in heme peroxidase and catalase mechanisms. Journal of Biological Chemistry 276(17): 13791-13796.

12. Kalghatgi S, Kelly CM, Cerchar E, Torabi B, Alekseev O, Fridman A, ... \& Azizkhan-Clifford J (2011) Effects of non-thermal plasma on mammalian cells. PloS One 6(1): e16270.

13. Keidar M, Walk R, Shashurin A, Srinivasan P, Sandler A, Dasgupta S, ... \& Trink B (2011) Cold plasma selectivity and the possibility of a paradigm shift in cancer therapy. British Journal of Cancer 105(9):1295-1301.

14. Kim YW, Byzova TV (2014) Oxidative stress in angiogenesis and vascular disease. Blood 123(5): 625-631.

15. Kraupp BG, Ruttkay-Nedecky B, Koudelka H, Bukowska K, Bursch W \& Schulte-Hermann, R (1995) In situ detection of fragmented DNA (TUNEL assay) fails to discriminate among apoptosis, necrosis, and autolytic cell death: a cautionary note. Hepatology 21(5): 1465-1468.

16. Laemmli U (1979) Slab gel electrophoresis: SDS-PAGE with discontinuous buffers. Nature 227: 680685.

17. Laroussi M (2015) Low-temperature plasma jet for biomedical applications: A review. IEEE Transactions on Plasma Science 43(3): 703-712.

18. Lee HJ, Shon CH, Kim YS, Kim S, Kim GC, Kong MG. (2009) Degradation of adhesion molecules of G361 melanoma cells by a non-thermal atmospheric pressure microplasma. New Journal of Physics 11(11):115026.

19. Lin D, Zhou Q, Xie X, Liu Y (2010) Potential biochemical and genetic toxicity of triclosan as an emerging pollutant on earthworms (Eisenia fetida). Chemosphere 81(10): 1328-1333.

20. Liu J, Xiong K, Ye X, Zhang J, Yang Y, Ji L (2015) Toxicity and bioaccumulation of bromadiolone to earthworm Eisenia fetida. Chemosphere 135: 250-256.

21. Liu M, Sun J, Sun Y, Bock C, Chen Q (2009) Thickness-dependent mechanical properties of polydimethylsiloxane membranes. Journal of Micromechanics and Microengineering, 19(3): 035028.

22. Lowe CN, Butt KR (2007) Earthworm culture, maintenance and species selection in chronic ecotoxicological studies: a critical review. European Journal of Soil Biology 43: S281-S288.

23. Lu X, Naidis GV, Laroussi M, Reuter S, Graves DB, Ostrikov K (2016) Reactive species in nonequilibrium atmospheric-pressure plasmas: Generation, transport, and biological effects. Physics Reports 630: 1-84.

24. MacManus JP, Hill IE, Huang ZG, Rasquinha I, Xue D, \& Buchan AM (1994) DNA damage consistent with apoptosis in transient focal ischaemic neocortex. Neuroreport 5(4): 493-496.

25. Misra NN, Pankaj SK, Segat A, Ishikawa K (2016) Cold plasma interactions with enzymes in foods and model systems. Trends in Food Science and Technology 55: 39-47.

26. Nastuta AV, Topala I, Grigoras C, Pohoata V, Popa G (2011) Stimulation of wound healing by helium atmospheric pressure plasma treatment. Journal of Physics D: Applied Physics 44(10): 105204. 
27. Ohkawa H, Ohishi N, Yagi K (1979) Assay for lipid peroxides in animal tissues by thiobarbituric acid reaction. Analytical Biochemistry 95: 351-358.

28. Partecke LI, Evert K, Haugk J, Doering F, Normann L, Diedrich S, ... \& Heidecke CD (2012) Tissue tolerable plasma (TTP) induces apoptosis in pancreatic cancer cells in vitro and in vivo. BMC Cancer 12(1): 1-10.

29. Pinzani P, Petruzzi E, Orlando C, Gallai R, Serio M, Pazzagli M (1998) Serum antioxidant capacity in healthy and diabetic subjects as determined by enhanced chemiluminescence. Journal of Bioluminescence and Chemiluminescence 13(5): 321-325.

30. Porter NA (1984) Chemistry of lipid peroxidation. In methods in enzymology (Vol. 105, pp. 273-282). Academic Press.

31. Schlegel J, Köritzer J, Boxhammer V (2013) Plasma in cancer treatment. Clinical Plasma Medicine 1(2): 2-7.

32. Shalata A, Tal M (1998) The effect of salt stress on lipid peroxidation and antioxidants in the leaf of the cultivated tomato and wild salt-tolerant relative Lycopersicon pennellii. Physiologia Plantarum 104:169-174

33. Sinkakarimi MH, Solgi E, Hosseinzadeh Colagar A (2020) Interspecific differences in toxicological response and subcellular partitioning of cadmium and lead in three earthworm species. Chemosphere 238: 124595.

34. Wilgus T A (2008) Immune cells in the healing skin wound: influential players at each stage of repair. Pharmacological Research 58(2): 112-116.

35. Xu GM, Shi XM, Cai JF, Chen SL, Li P, Yao CW, ... \& Zhang GJ (2015) Dual effects of atmospheric pressure plasma jet on skin wound healing of mice. Wound Repair and Regeneration 23(6): 878-884.

36. Xue YG, Gu XY, Wang XR, Sun C, Xu XH, Sun J, Zhang BG (2009) The hydroxyl radical generation and oxidative stress for the earthworm Eisenia fetida expose to tetrabromobisphenol A. Ecotoxicology 18: 693-699.

37. Yasuda M, Umemura S, Osamura RY, Kenjo T, \& Tsutsumi Y (1995) Apoptotic cells in the human endometrium and placental villi: pitfalls in applying the TUNEL method. Archives of Histology and Cytology 58(2): 185-190.

\section{Figures}



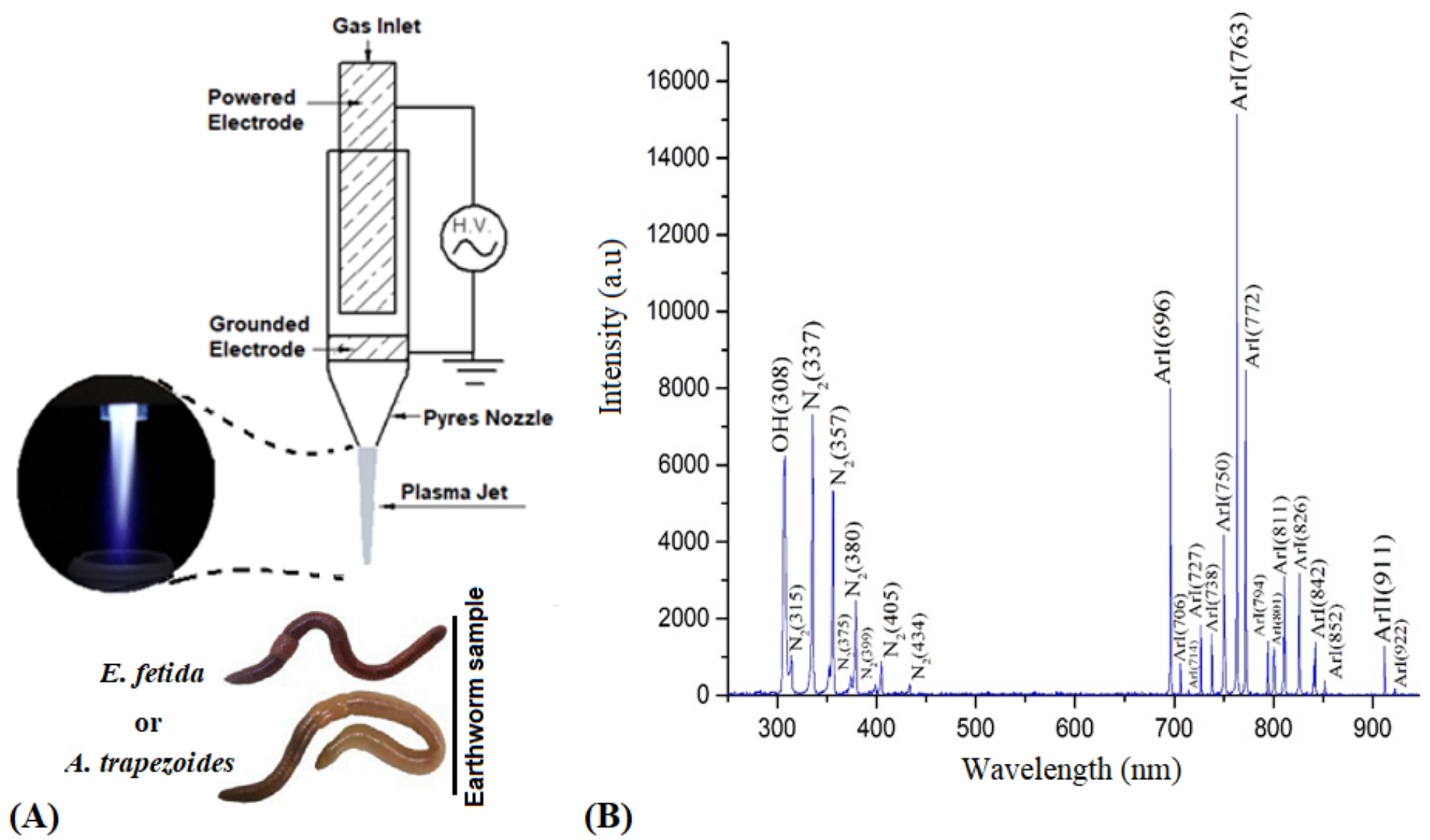

(B)

\section{Figure 1}

Schematic drawing of APPJ device, Earthworm treatment, and highlighted spectral lines of the APPJ: A) APPJ device and Earthworm treatment; B) Optical emission spectroscopy above of the sample which showed some highlighted spectral lines such as reactive atomic oxygen and hydroxyl as products of the plasma jet. Although the relative concentration of the $\mathrm{OH}$ seems to be low, the concentration of reactive $\mathrm{OH}$ grows significantly due to the collision between air, humidity, and meta-stable excited argon (Retrieved from Hosseinzadeh Colagar et al. 2020, with a little change).

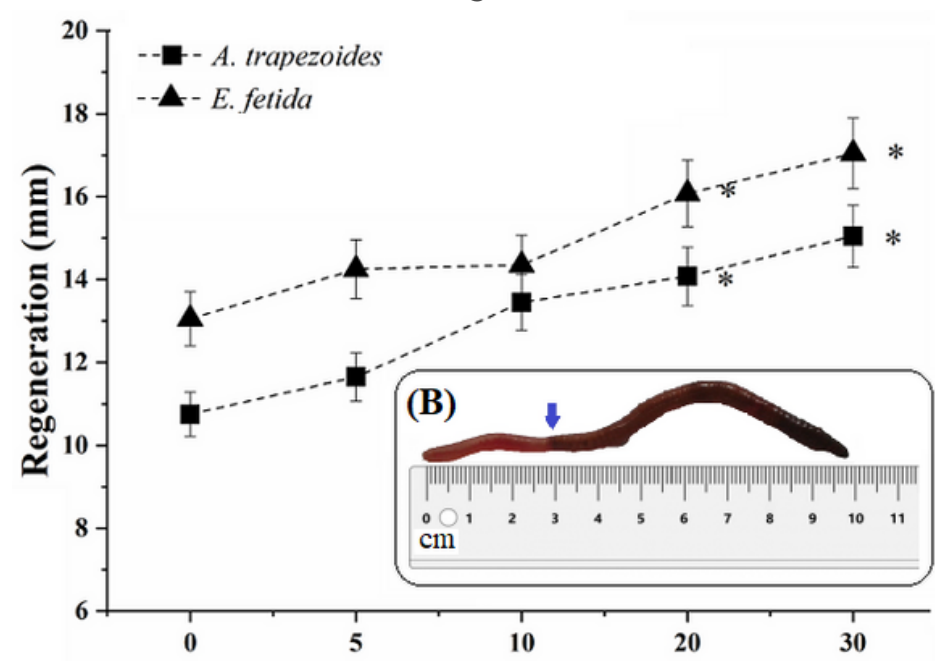

(A)

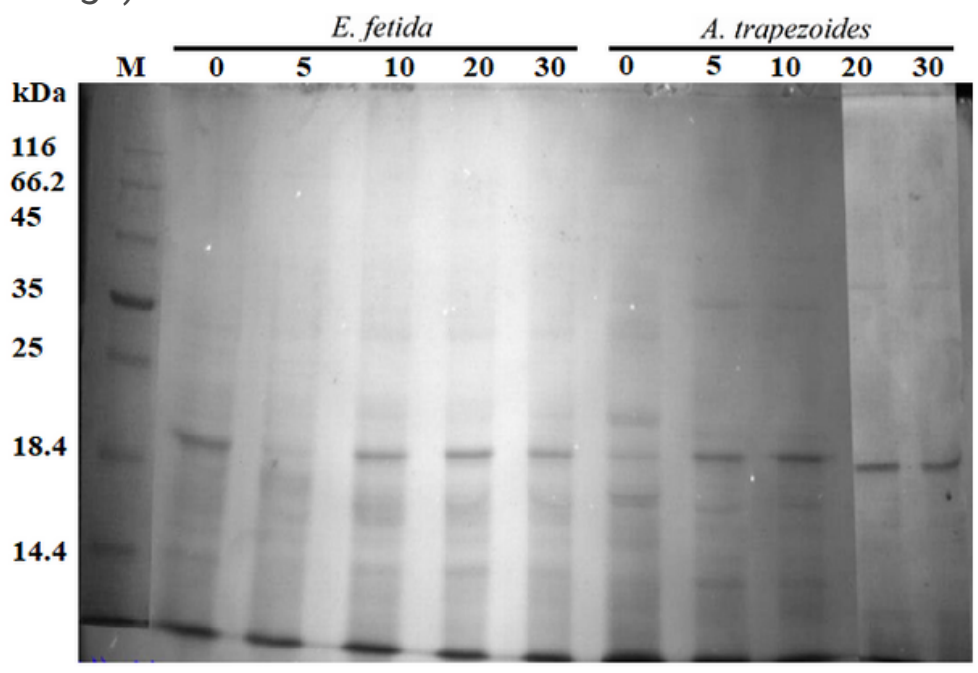

(C) 
Figure 2

Effects of different exposure time of APPJ on A. trapezoides and E. fetida: A) Effects of different exposure time of APPJ on the regeneration; B) Rounded rectangle box were showed photographs of an earthworm having part of its tail cut, which APPJ plasma discharged for $30 \mathrm{~s}$, and then left in conditions to grow back; Arrow indicates the location of the earthworm segments $18-21$; $\mathrm{cm}=$ centimeter; C) Effects of different exposure time of APPJ on the protein pattern of the coelomic fluid proteins, $M=$ Protein marker.
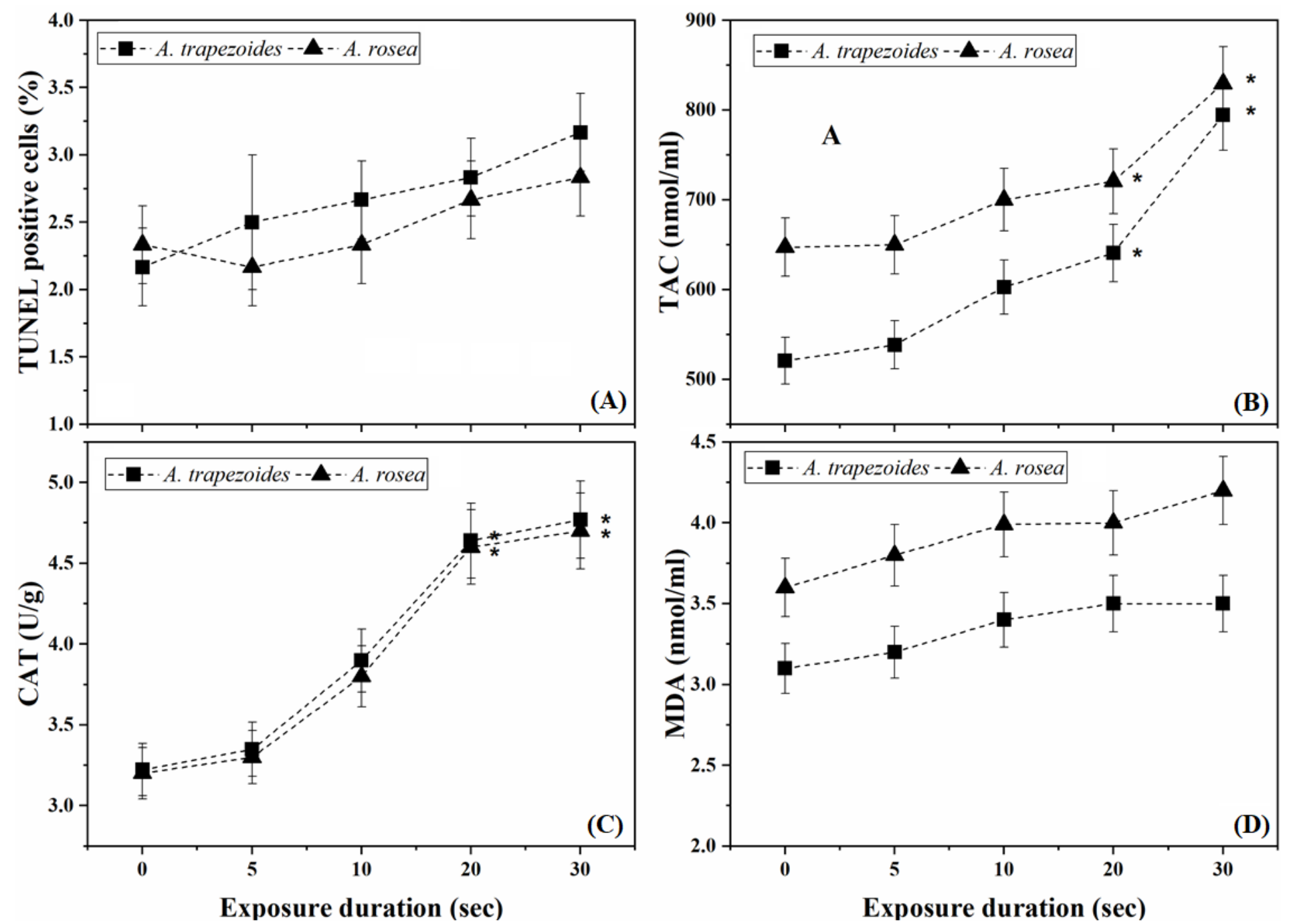

\section{Figure 3}

Effects of different exposure times of APPJ on cell death, TAC, CAT, and MDA: A) cell death in A. trapezoides and E. fetida species: B) TAC; C) Catalase/ CAT; D) MDA (D). Asterisks (*) indicates significant differences $(p<0.05)$ between treatments and the control. 